\title{
RELATIONSHIPS BETWEEN BACKFAT THICKNESS, MILK YIELD AND FERTILITY TRAITS WITH RESULTING STANDARD CURVES AND THEIR APPLICATION IN DAIRY HERD MANAGEMENT
}

\author{
U. Schröder, R. Staufenbiel
}

Klinik für Klauentiere der Freien Universität Berlin

The target of this study is to describe the interactions between the development of body condition in course of lactation and some descriptors of yield and fertility. It is aimed to identify a conditional area to be used in dairy herd management, which renders possible to combine high milk yield with acceptable fertility traits and minimal health disorders. For this purpose, backfat thickness was measured by ultrasound at about 46000 dairy cows on 75 different farms and related to production variables.

Negative energy balance is getting more intense and prolonged with increasing milk yield. However a conditional nadir below $10 \mathrm{~mm}$ leads to decreasing milk production. Adequate feeding adjusted to milk yield seems to be a problem within herds. After depletion of nearly all their energy deposits high-performance animals are not able to restore an adequate amount of fat reserves until next parturition. On the other hand the low-producing herdmates are predisposed to becoming excessively fat in late lactation. To reach a high production level without an increasing incidence of health disorders, conditional nadir should not be below $13 \mathrm{~mm}$ on herd average. Lower values only lead to negligibly higher milk yields but cause a distinctively higher risk of culling and an extreme energy deficit.

The development of body condition is strongly related to the milk protein content. The average protein percentage of total lactational milk should be between 3,5\% and 3,8\%. Values below 3,2\% refer to an extreme energy deficit in early lactation.

Intervals to first artificial insemination and to conception get longer with increasing amounts of body fat losses in early lactation. To reach good reproductive performance, conditional nadir should not be below $13 \mathrm{~mm}$ on herd average.

Independent of dairy merit mean body condition in the dry period should range from 22 to $24 \mathrm{~mm}$. High reproductive efficiency and low culling risks can be observed in this conditional area.

Animals should return to positive energy balance after at least 100 days in milk and another 100 days later a marked regeneration of body fat reserves should be realised. At drying off, animals should have regained their calving condition. High producing dairy cows however have to increase their condition in the dry period, because replenishment of body energy reserves during late lactation becomes increasingly difficult.

The validity of body condition scoring is limited concerning the individual, but it is a useful management tool to assess the nutritional status of a dairy herd. It is a practical instrument in controlling the physiological loss of body fat reserves in early lactation and to realise an adequate replenishment of body tissue reserves in anticipation of the subsequent lactation. It is shown that high herd yields don't have to be at expense of reproductive performance and can be achieved without extreme body condition losses. In conclusion, an efficient herd management can offset depression in fertility, which commonly is the price for an increasing milk yield. 